\title{
An improved method to determine the absolute abundance of glycerol dibiphytanyl glycerol tetraether lipids
}

\author{
Carme Huguet $^{\mathrm{a}, *}$, Ellen C. Hopmans ${ }^{\mathrm{a}}$, Wilma Febo-Ayala ${ }^{\mathrm{b}}$, \\ David H. Thompson ${ }^{\text {b }}$, Jaap S. Sinninghe Damsté ${ }^{\text {a }}$, Stefan Schouten ${ }^{\text {a }}$ \\ ${ }^{a}$ Royal Netherlands Institute for Sea Research (NIOZ), Department of Marine Biogeochemistry and Toxicology, P.O. Box 59, 1790 \\ AB Den Burg, Texel, The Netherlands \\ ${ }^{\mathrm{b}}$ Purdue University, Department of Chemistry, 560 Oval Drive, West Lafayette, IN 47907-2038, USA
}

Received 17 March 2006; received in revised form 23 May 2006; accepted 24 May 2006

Available online 24 July 2006

\begin{abstract}
Isoprenoid glycerol dialkyl glycerol tetraethers (GDGTs) are specific membrane lipids derived from archaea, one of the three domains of life. These lipids can be used as biomarkers in paleo-ecological studies. GDGTs can be analyzed by high performance liquid chromatography (HPLC)/mass spectrometry (MS). To quantify GDGTs, external standard curves were run monthly on the HPLC/MS. However, external standard curves represented a snapshot and do not adjust for changes during storage, dissolution and manipulation of samples or drifts in HPLC/MS conditions. To measure absolute GDGT abundances more accurately, we tested the use of a newly synthesized $\mathrm{C}_{46}$ GDGT as an internal standard. The accuracy in the determination of GDGT concentration improved significantly when using the internal standard ( $5 \%$ standard deviation) compared to that obtained with the monthly external standard curve ( $43 \%$ standard deviation). Thus, the new internal standard technique will greatly improve the accuracy of GDGT abundance measurements, increase the potential of GDGTs in paleo-ecological studies.
\end{abstract}

(C) 2006 Elsevier Ltd. All rights reserved.

\section{Introduction}

Archaea are prokaryotes which are phylogenetically distinct from bacteria and possess different membrane lipids. While bacterial membranes are generally formed by straight-chain fatty acids ester bound to glycerol, membranes of dominant archaeal groups contain lipids with isoprenoid alkyl chains bound by ether bonds (Fig. 1). Most of the

\footnotetext{
* Corresponding author. Tel.: +31 222 369569; fax: +31 222 319674.

E-mail address: huguet@nioz.nl (C. Huguet).
}

cultured members of the archaeal domain producing isoprenoid glycerol dialkyl glycerol tetraethers (GDGTs) are extremophiles, but recent investigations showed that crenarchaeota, a subgroup of archaea, are ubiquitous and abundant in seawater (Hoefs et al., 1997; Massana et al., 2000; Karner et al., 2001) and lakes (Powers et al., 2004). GDGTs biosynthesized by these crenarchaeota are similar to those of their thermophilic ancestors, except for crenarchaeol, a unique GDGT containing one cyclohexane moiety in addition to the more common cyclopentane moieties (Sinninghe Damsté et al., 2002a). It is thought that the biosynthesis of 


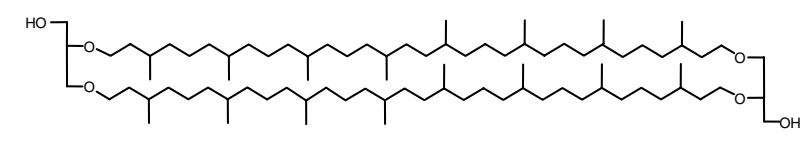

GDGT-0

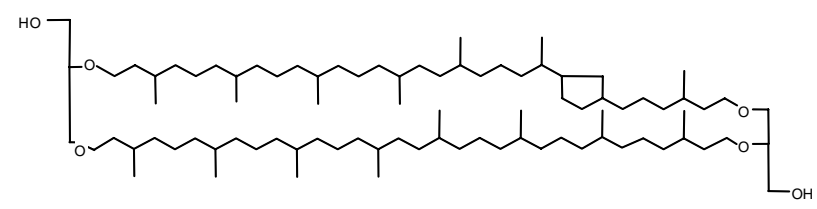

GDGT-1
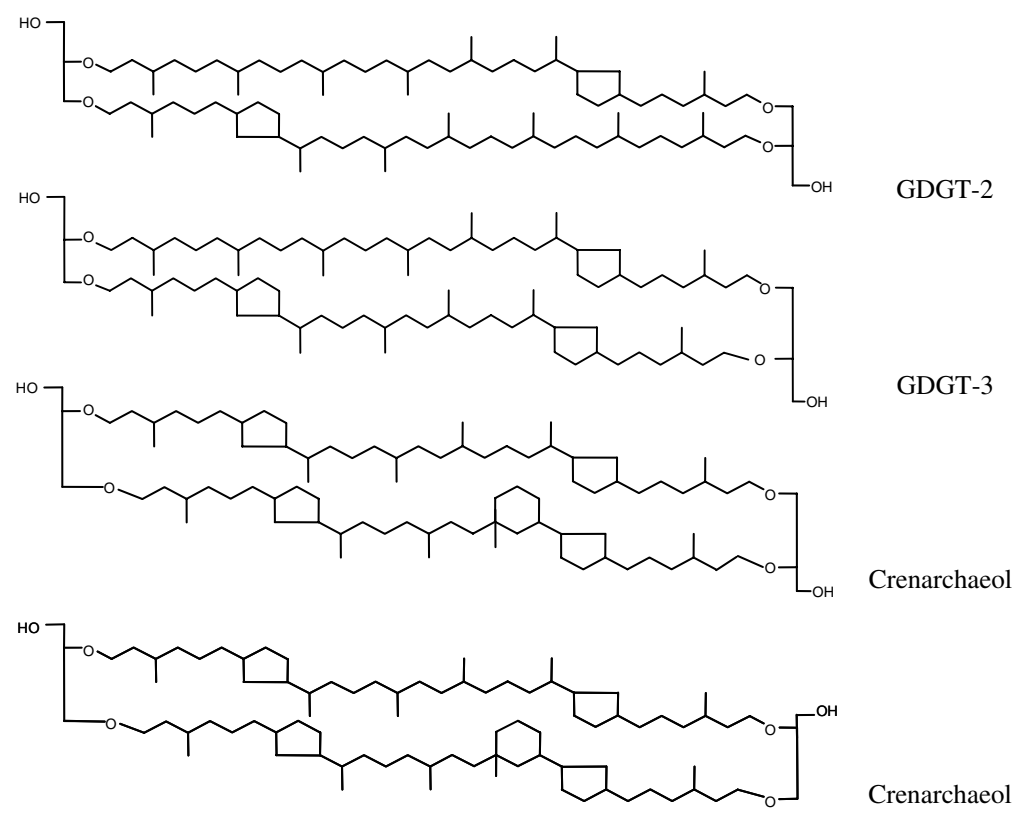

Crenarchaeol isomer

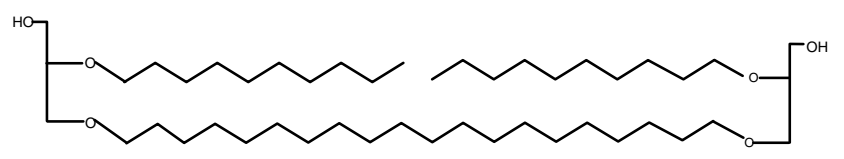

$\mathrm{C}_{46}$ GDGT

Fig. 1. Molecular structures of protonated GDGT molecules and the internal standard, $\mathrm{C}_{46}$ GDGT.

crenarchaeol is an adaptation to the relatively cold sea water temperatures, compared to thermophilic environments such as hot springs (Kuypers et al., 2002). For this reason, crenarchaeol (Fig. 1) is a taxonomically-specific biomarker for non-thermophilic crenarchaeota.

Crenarchaeol has been used to study the abundance of crenarchaeota in the Arabian Sea (Sinninghe Damsté et al., 2002b) and the Black Sea (Wakeham et al., 2003). Results of these studies are in general agreement with those of molecular biological studies which show that crenarchaeota occur throughout the water column (e.g. Karner et al., 2001). GDGTs are separated with high performance liquid chromatography (HPLC) and then identified by mass spectrometry (MS) (Hopmans et al., 2000). To quantify the GDGTs for the above studies, external standard curves were run, using a GDGT-0 standard (Fig. 1) (Wakeham et al., 2003). However, this technique is likely not very accurate for calculating absolute abundances as it does not account for differences in the extraction, processing, storage of the samples and drifts in MS response. Hence, the changes observed in the relative abundances in depth profiles such as those noted in the Black Sea and the Arabian Sea may be reliable, but the calculated absolute amounts might be less precise. The best way to improve the analytical accuracy in the quantification of GDGTs is to use an internal standard that can be added at the beginning of the extraction process. This internal standard should not occur naturally and needs 
to be chemically similar to the GDGTs quantified. Here, we tested a $\mathrm{C}_{46}$ GDGT which was synthesized by Patwardhan and Thompson (1999), and compared GDGT absolute abundance measurements using this new internal standard to those calculated with the external standard curve technique for the same set of samples.

\section{Experimental}

As an internal standard we used a GDGT with two glycerol head groups linked by a $\mathrm{C}_{20}$ alkyl chain and two $\mathrm{C}_{10}$ alkyl chains (Fig. 1) which was synthesized by Patwardhan and Thompson (1999). A mixture of the $\mathrm{C}_{46}$ GDGT and crenarchaeol (1:1 w:w) was prepared and analyzed every week over a four month period to determine the relative response factor (RRF). To produce the external standard curves we used crenarchaeol as isolated previously (Sinninghe Damsté et al., 2002b) and injected amounts ranging from 10 to $200 \mathrm{ng}$. Both the internal and external standard quantification methods were tested by analyzing GDGTs in a sediment sample from the Drammensfjord $\left(59^{\circ} 40^{\prime} \mathrm{N} 10^{\circ} 23^{\prime} \mathrm{E}\right)$. The sediment sample was a composite sample from a core taken in the centre of the Drammensfjord with the RV 'Pelagia' on October 29th, 1999 (Smittenberg et al., 2005). The core was freeze dried and ground to produce a homogenous sample. The freeze dried sediment sample was extracted using an Accelerated Solvent Extractor 200 (ASE 200, DIONEX) with a mixture of dichloromethane (DCM) and methanol (MeOH) (9:1 vol:vol) at $100{ }^{\circ} \mathrm{C}$ and $7.6 \times 10^{6} \mathrm{~Pa}$. A solution of the $\mathrm{C}_{46}$ GDGT in $99 \% \quad n$-hexane: $1 \%$ isopropanol $(0.01 \mathrm{mg} / \mathrm{ml})$ was added to the total extract, with a proportion of $750 \mathrm{ng}$ of the $\mathrm{C}_{46}$ GDGT for $1 \mathrm{mg}$ of total extract. The total extract was separated using a glass pipette column filled with activated alumina by sequentially eluting with hexane/DCM (9:1 vol:vol) to obtain an apolar fraction and $\mathrm{DCM} / \mathrm{MeOH}$ (1:1 vol:vol) to obtain a polar fraction. The polar fraction containing the GDGTs was filtered through a $0.45 \mu \mathrm{m}$ pore size, $4 \mathrm{~mm}$ diameter PFTE filter prior to injection. The samples were analyzed by HPLC-atmospheric pressure positive ion chemical ionization mass spectrometry (APCI)-MS by applying conditions slightly modified from Hopmans et al. (2000). Analyses were performed with an HP 1100 Series HPLC/MS equipped with an auto-injector and ChemStation chromatography manager software. Separation was achieved on a Prevail Cyano column $(2.1 \times 150 \mathrm{~mm}, 3 \mu \mathrm{m}$; Alltech, Deerfield, Illinois, USA), maintained at $30^{\circ} \mathrm{C}$. The GDGTs were first eluted isocratically with (A) hexane and (B) propanol as follows, $99 \% \mathrm{~A}: 1 \% \mathrm{~B}$ for $5 \mathrm{~min}$, then a linear gradient to $1.8 \% \mathrm{~B}$ in $45 \mathrm{~min}$. Flow rate was $0.2 \mathrm{ml} /$ min. After each analysis the column was cleaned by back flushing hexane/propanol (90:10, vol:vol) at $0.2 \mathrm{ml} / \mathrm{min}$ for $10 \mathrm{~min}$. Conditions for APCI/MS were as follows: nebulizer pressure 60 psi, vaporizer temperature $400{ }^{\circ} \mathrm{C}$, drying gas $\left(\mathrm{N}_{2}\right)$ flow $6 \mathrm{l} / \mathrm{min}$ and temperature $200^{\circ} \mathrm{C}$, capillary voltage $-3.5 \mathrm{kV}$, corona $5 \mu \mathrm{A}(\sim 3.2 \mathrm{kV})$. Mass spectra of the $\mathrm{C}_{46}$ GDGT and crenarchaeol were obtained by scanning $m / z$ 800-1500. For the standard curves and GDGT quantification single ion monitoring (SIM) was used instead of mass scanning because SIM improves the signal to noise ratio and thus improves the reproducibility. SIM parameters were set to detect the protonated molecules of the five isoprenoid GDGTs $(m / z$ 1302, 1300, 1298, 1296, 1292) as well as the protonated molecule of the $\mathrm{C}_{46}$ GDGT internal standard $(m / z$ 744), with a dwell time of $237 \mathrm{~ms}$ per ion.

\section{Results and discussion}

\subsection{HPLC/MS analysis of the $C_{46} G D G T$}

Analysis of the apolar and polar fraction of the Drammensfjord sample showed that the $\mathrm{C}_{46}$ GDGT eluted in the same fraction as the GDGTs, i.e. the polar fraction. The $\mathrm{LC}$ retention time of the $\mathrm{C}_{46}$ GDGT varied between 22.5 and $23.3 \mathrm{~min}$, eluting immediately after crenarchaeol ( $\sim 21 \mathrm{~min})$. The mass spectrum of the $\mathrm{C}_{46}$ GDGT shows a predominant protonated molecule $\left([\mathrm{M}+\mathrm{H}]^{+}\right.$, Fig. 2a). There is a minor fragment due to loss of an $\mathrm{OH}$ group $(-18 \mathrm{Da})$ but the most abundant fragment results from the loss of one of the $\mathrm{C}_{10}$ chains $(-140 \mathrm{Da})$ and the subsequent loss of an $\mathrm{OH}$ group $(-158 \mathrm{Da})$. The second most abundant fragment is the loss of a $\mathrm{C}_{10}$ alkyl chain and glycerol group (-232 Da) (Fig. 2a). In comparison, mass spectra of isoprenoid GDGTs are dominated by the $[\mathrm{M}+\mathrm{H}]^{+}$protonated molecule and only show minor fragments due to losses of 18 and $74 \mathrm{Da}$, which correspond to the loss of an $\mathrm{OH}$ and a glycerol group, respectively (Hopmans et al., 2000; Fig. 2b). The difference in fragmentation pattern is due to the fact that the $\mathrm{C}_{46}$ GDGT is not a macrocyclic compound in contrast to the isoprenoid GDGTs. 

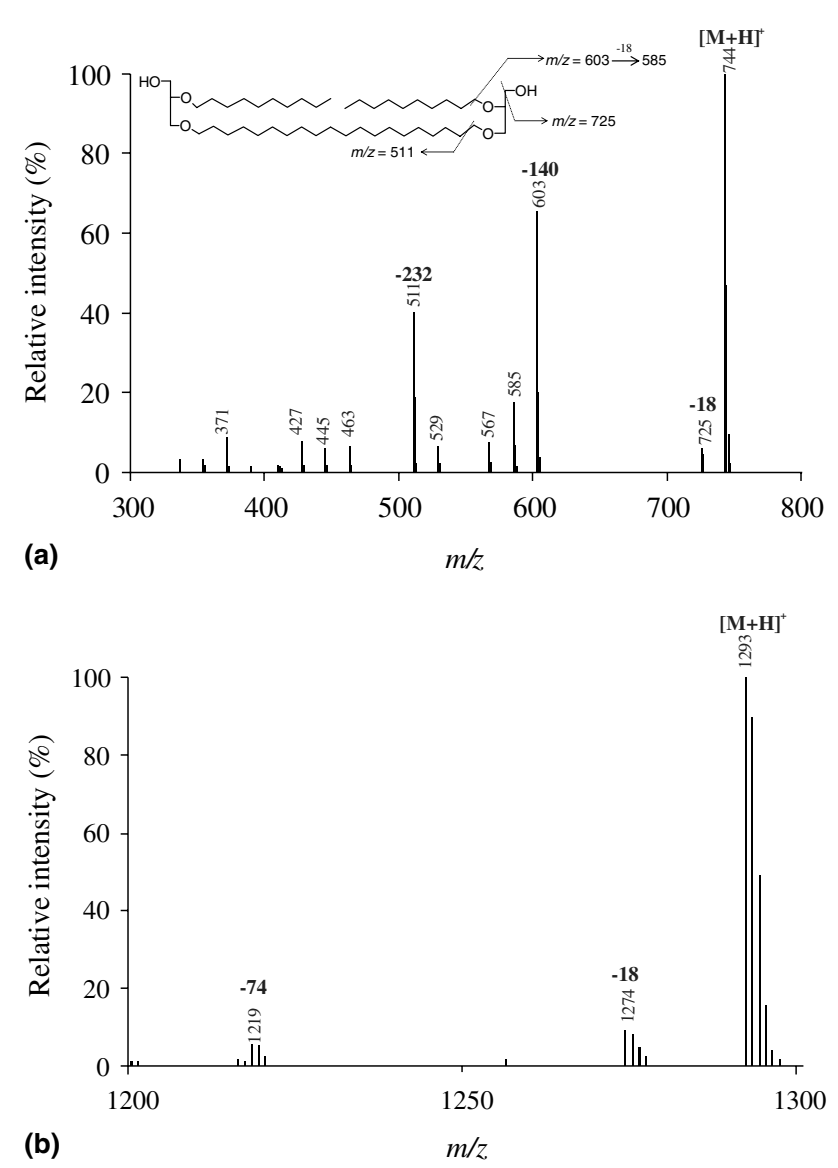

Fig. 2. APCI mass spectrum of: (a) $\mathrm{C}_{46} \operatorname{GDGT}(\mathrm{m} / \mathrm{z}$ 743) and (b) crenarchaeol $(\mathrm{m} / \mathrm{z}$ 1292). Mass spectra have been corrected for background.

\subsection{Relative response factor}

The response factor of both the $\mathrm{C}_{46}$ GDGT and crenarchaeol on the HPLC/MS was determined by SIM of both compounds at a range of concentrations (Fig. 3). The response factor of crenarchaeol is much higher than that of the $\mathrm{C}_{46}$ GDGT, i.e. 44.8 arbitrary units per ng injected GDGT versus 6.9 arbitrary units per ng injected GDGT respectively. This is likely due to the enhanced fragmentation of the $\mathrm{C}_{46}$ GDGT compared to crenarchaeol, which results in a relatively lower abundance of the protonated molecule (Fig. 2). Depending on source conditions and calibration of the MS, differences may occur in the relative fragmentation pattern of the $\mathrm{C}_{46}$ GDGT over time. This would affect the response factor as the protonated molecule then represents a changing percentage of the total ion signal over time. To assess this, the difference in response factor between the $\mathrm{C}_{46}$ GDGT and crenarchaeol was measured over time. For this, a standard mixture of $\mathrm{C}_{46}$ GDGT and crenarchaeol $(1: 1 \mathrm{w}: \mathrm{w})$ was analyzed once every week, over a four month period to determine the relative response factor (RRF). The RRF was calculated as follows:

$\mathrm{RRF}=\frac{(\text { Area crenarchaeol })}{\left(\text { Area } \mathrm{C}_{46}\right)} \times \frac{(\text { Weight crenarchaeol })}{\left(\text { Weight } \mathrm{C}_{46}\right)}$

The RRF changed frequently, with values ranging between 2.9 and 4.8 (Fig. 4). During this study, the HPLC/MS conditions regularly changed due to power cuts and re-calibration of the MS (black arrows, Fig. 4). The most marked changes in RRF occurred after the first power cut (Fig. 4a) when the ratio changed from 4.2 to 4.8 and after MS re-calibrations when RRF values dropped from 4.7 to 3.8 and 3.8 to 2.9 , respectively (Fig. $4 \mathrm{~b}$ and d). Primary reasons for these large changes are changing conditions in the APCI source and loss of mass accuracy 


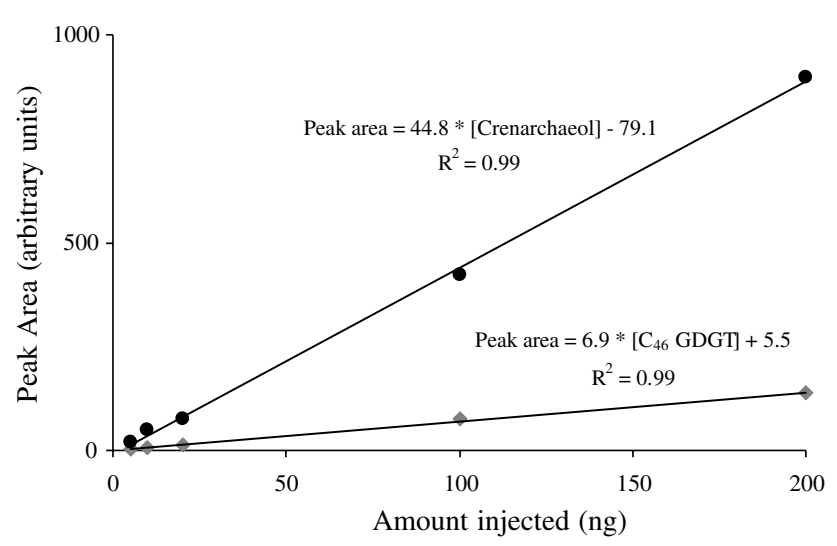

Fig. 3. Standard curves of amount injected versus peak area for crenarchaeol and $\mathrm{C}_{46}$ GDGT.

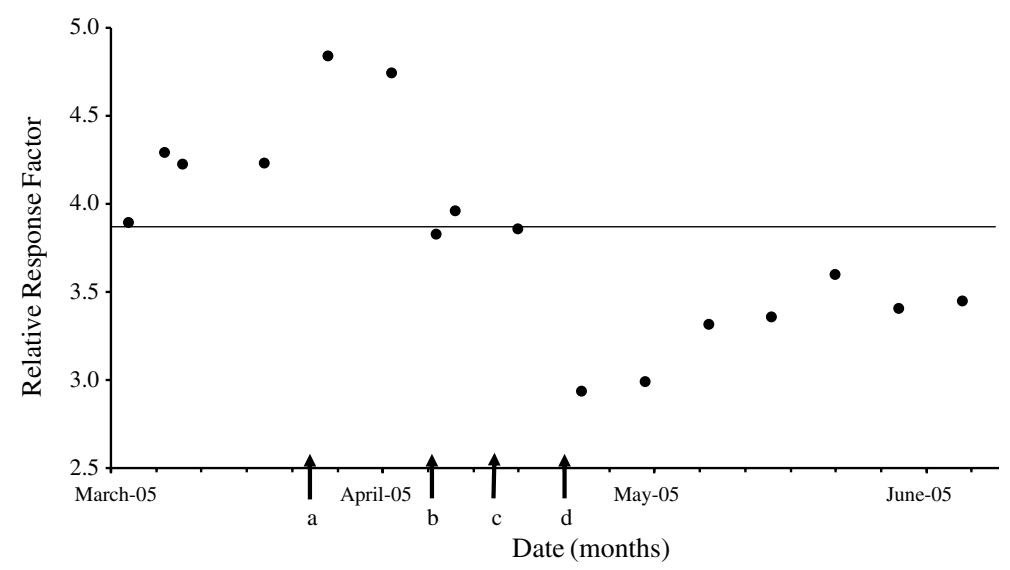

Fig. 4. Variation of the relative response factor over time. The average value is indicated by the black line. Black arrows signal changes in the HPLC/MS conditions: (a) power cut, (b) re-tuning, (c) change of parts and air-conditioning restored and (d) MS re-tuning and a power cut.

due to drifting of the mass axis. The first will change the relative degree of in-source fragmentation of the internal standard and the relative degree of ionization. The latter factor will induce changes in the RRF due to the large mass difference between the internal standard and the GDGTs. This shows that the RRF needs to be determined regularly and in particular after HPLC/MS conditions have changed.

\subsection{Quantification of GDGTs using internal and external standards}

Over the same period of time that the RRF stability was evaluated, we also measured GDGT abundances in a Drammensfjord sediment sample using both the internal and the external standard. These analyses were performed once every two weeks, directly after determining the RRF value The external standard curves were determined on a monthly basis and after major alterations in the MS conditions (e.g. MS re-calibration). When calculating the absolute GDGT abundances obtained using either the internal or external standard, similar average GDGT concentrations are obtained for both methods (Fig. 5). However, the relative standard deviation is much higher when using the external standard curves $(43 \%)$ than with the $\mathrm{C}_{46}$ GDGT internal standard (5\%). This is likely because the internal standard undergoes the same work up as that of the sedimentary GDGTs. In addition, the internal standard is measured at the same time as the sample, thus reducing errors due to drifts in HPLC/MS conditions that cannot be accurately measured with an external standard. Hence, for GDGT absolute abundance measure- 


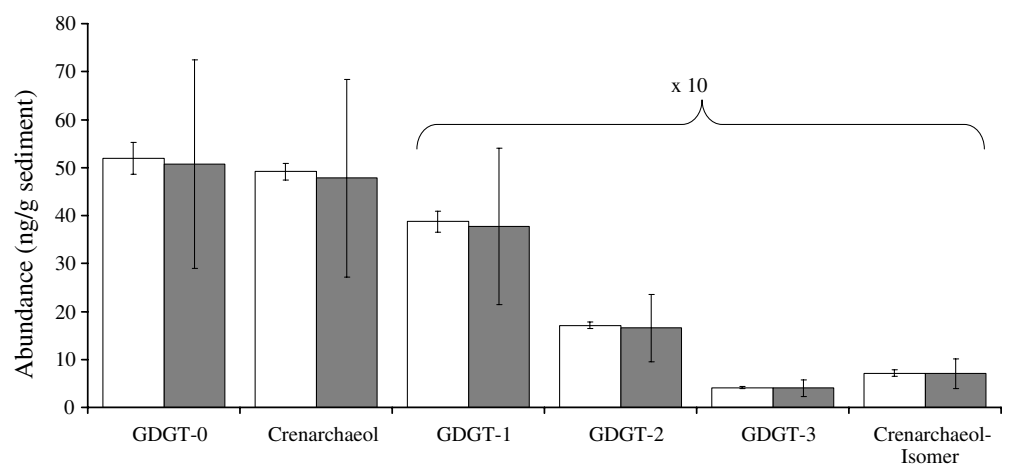

Fig. 5. Abundance of GDGT molecules in Drammensfjord sediments, calculated with internal standard (open bars) and external standard (grey bars). Relative standard deviations are shown by the vertical bars. The abundance of GDGT-1, GDGT-2, GDGT-3 and the crenarchaeol isomer are multiplied by 10 .

ments the use of an internal standard will lead to improved accuracy of quantification.

\section{Acknowledgements}

Two anonymous reviewers and Dr. Simon George are thanked for constructive comments. This project was supported by NWO-ALW (Project Nr. 152911).

\section{Associate Editor-S.C. George}

\section{References}

Hoefs, M.J.L., Schouten, S., deLeeuw, J.W., King, L.L., Wakeham, S.G., Sinninghe Damsté, J.S., 1997. Ether lipids of planktonic archaea in the marine water column. Applied and Environmental Microbiology 63, 3090-3095.

Hopmans, E.C., Schouten, S., Pancost, R.D., van der Meer, M.T.J., Sinninghe Damsté, J.S., 2000. Analysis of intact GDGT lipids in archaeal cell material and sediments by high performance liquid chromatography/atmospheric pressure chemical ionization mass spectrometry. Rapid Communications in Mass Spectrometry 14, 585-589.

Karner, M.B., DeLong, E.F., Karl, D.M., 2001. Archaeal dominance in the mesopelagic zone of the Pacific Ocean. Nature 409, 507-510.

Kuypers, M.M.M., Blokker, P., Hopmans, E.C., Kinkel, H., Pancost, R.D., Schouten, S., Sinninghe Damsté, J.S., 2002. Archaeal remains dominate marine organic matter from the early Albian oceanic anoxic event 1b. Palaeogeography Palaeoclimatology Palaeoecology 185, 211-234.

Massana, R., DeLong, E.F., Pedrós-Alió, C., 2000. A few cosmopolitan phylotypes dominate planktonic archaeal assemblages in widely different oceanic provinces. Applied and Environmental Microbiology 66, 1777-1787.

Patwardhan, A.P., Thompson, D.H., 1999. Efficient synthesis of 40-and 48-membered tetraether macrocyclic bisphosphocholines. Organic Letters 1, 241-243.

Powers, L.A., Werne, J.P., Johnson, T.C., Hopmans, E.C., Sinninghe Damsté, J.S., Schouten, S., 2004. Crenarchaeotal membrane lipids in lake sediments: a new paleotemperature proxy for continental paleoclimate reconstruction? Geology 32, 613-616.

Sinninghe Damsté, J.S., Schouten, S., Hopmans, E.C., van Duin, A.C.T., Geenevasen, J.A.J., 2002a. Crenarchaeol: the characteristic core glycerol dibiphytanyl glycerol tetraether membrane lipid of cosmopolitan pelagic crenarchaeota. Journal of Lipid Research 43, 1641-1651.

Sinninghe Damsté, J.S., Rijpstra, W.I.C., Hopmans, E.C., Prahl, F.G., Wakeham, S.G., Schouten, S., 2002b. Distribution of membrane lipids of planktonic Crenarchaeota in the Arabian sea. Applied and Environmental Microbiology 68, 2997-3002.

Smittenberg, R.H., Baas, M., Green, M.J., Hopmans, E.C., Schouten, S., Sinninghe Damsté, J.S., 2005. Pre- and postindustrial environmental changes as revealed by the biogeochemical sedimentary record of Drammensfjord, Norway. Marine Geology 214, 177-200.

Wakeham, S.G., Lewis, C.M., Hopmans, E.C., Schouten, S., Sinninghe Damsté, J.S., 2003. Archaea mediate anaerobic oxidation of methane in deep euxinic waters of the Black Sea. Geochimica et Cosmochimica Acta 67, 1359-1374. 